\title{
Anesthetics Eliminate Somatosensory-Evoked Discharges of Neurons in the Somatotopically Organized Sensorimotor Striatum of the Rat
}

\author{
Mark O. West \\ Department of Psychology, Rutgers University, New Brunswick, New Jersey 08903
}

The somatotopic organization of the lateral striatum has been demonstrated by anatomical studies of corticostriatal projections from somatosensory and motor cortices and by single-cell recordings in awake animals. The functional organization in the rat, characterized thus far in the freely moving rat preparation, could be mapped more precisely if a stereotaxic, and possibly an anesthetized, preparation could be used. Because striatal discharges evoked by innocuous somatosensory stimulation are used in mapping, this study tested whether such discharges can be observed during anesthesia, encouraged by responsiveness during anesthesia in somatosensory cortical layers projecting to the striatum. Electrode tracks through lateral striatum of anesthetized rats (pentobarbital or ketamine) revealed spontaneously discharging neurons but no discharges evoked by somatosensory examination (passive manipulation and cutaneous stimulation of 14 body parts). Similar tracks in chronically implanted rats showed evoked firing at numerous sites during wakefulness but not during anesthesia (pentobarbital or urethane). Comparisons of the activity of individual neurons between wakefulness and anesthesia showed that pentobarbital, ketamine, chloral hydrate, urethane, or metofane eliminated evoked firing and suppressed spontaneous firing. Recovery time was greater for neural than for behavioral measures. Thus, mapping as proposed is ruled out, and more importantly, the data show that somatotopically organized lateral striatal neurons stop discharging in response to natural stimulation during anesthesia. Available data indicate they do not reach threshold in response to depolarizations produced by glutamatergic corticostriatal synaptic transmission projected from the somatosensory cortex. These data and demonstrations of anestheticinduced imbalances in most striatal neurotransmitters emphasize that many results regarding striatal physiology and pharmacology during anesthesia cannot be extrapolated to behavioral conditions, thus indicating the need for more empirical testing in conscious animals.

Key words: striatum; putamen; somatosensory; anesthesia; neurons; corticostriatal; neurophysiology
The lateral striatum of primates receives topographic projections from primary motor (MI) and somatosensory (SI) cortices, creating a patchy somatotopy (Kunzle, 1975, 1977; Selemon and Goldman-Rakic, 1985; Flaherty and Graybiel, 1993, 1994). This has been corroborated by electrophysiological data (Liles, 1979; Crutcher and DeLong, 1984a; Alexander and DeLong, 1985) that correspond directly to the topography and patchiness of corticostriatal inputs (Liles and Updyke, 1985). Likewise in rats, the distribution and somatotopic organization of striatal neurons related functionally to individual body parts (Carelli and West, 1991; Mittler et al., 1994; Cho and West, 1997) correspond to topographies of SI and MI corticostriatal projections (McGeorge and Faull, 1989; Ebrahimi et al., 1992; Kincaid and Wilson, 1996). Functional properties of striatal neurons parallel those of SI and MI neurons (Evarts, 1974; Lemon and Porter, 1976; Fetz et al., 1980; Soso and Fetz, 1980; Chapin and Woodward, 1981, 1986; Chapin and Lin, 1984; Tanji and Kurata, 1985; Chapin, 1986; Favorov et al., 1988; Crutcher and Alexander, 1990; Stern et al., 1997) and may reflect convergence of SI and MI corticostriatal

\footnotetext{
Received March 18, 1998; revised Aug. 6, 1998; accepted Aug. 13, 1998.

This work was supported by National Science Foundation Grant BNS-8708523, National Institute on Drug Abuse Grant DA 04551, and Public Health Service Grant RR 07058. Discussions of this work with Taliah Mittler and Laura Peoples and the technical assistance of Karamarie Fecho, Anthony Pawlak, Dawn Duke, Fred Gee, and Linda King are gratefully acknowledged.

Correspondence should be addressed to Dr. Mark West, Department of Psychology, Rutgers University, New Brunswick, NJ 08903.

Copyright (C) 1998 Society for Neuroscience $\quad 0270-6474 / 98 / 189055-14 \$ 05.00 / 0$
}

projections (West et al., 1990; Carelli and West, 1991; Flaherty and Graybiel, 1993). Because other striatal afferents show little correspondence to these striatal features (Peschanski et al., 1981; Steinfels et al., 1981; DeLong et al., 1983; Schultz et al., 1983; Schultz, 1986; Romo and Schultz, 1990; Ljungberg et al., 1992; Chudler and Dong, 1995), the transmission of detailed somatosensory and motor information to the somatotopically organized lateral striatum is attributable to the corticostriatal system.

Detailed three-dimensional reconstructions of the lateral striatum, based on locations of sensorimotor-activated neurons and their clusters, were obtained for individual monkeys during head restraint (Crutcher and DeLong, 1984a; Alexander and DeLong, 1985) but have not been readily obtainable with freely moving rats. In individual rats, similar maps would be valuable for comparison with patch/matrix compartmentalization (Donoghue and Herkenham, 1986; Gerfen, 1989; Trytek et al., 1996) and for evaluating hypotheses based on the detail of corticostriatal projections (Kincaid et al., 1998). Precise mapping could be accomplished if a stereotaxic could be used, possibly with the anesthetized rat preparation. But this would require that, during anesthesia, striatal neurons discharge in response to innocuous somatosensory stimulation, as they do during wakefulness (Carelli and West, 1991). Indeed they might, given that SI has been accurately mapped during anesthesia because of the responsiveness of SI neurons (Welker, 1971, 1976; Hall and Lindholm, 1974; Armstrong-James, 1975; Waterhouse and Woodward, 1980; Lamour et al., 1983; Chapin, 1986; Stryker et al., 1987; Simons et 
al., 1992), including those in layers III and V from which SI corticostriatal projections arise (Kincaid and Wilson, 1996). Previously, striatal neurons in anesthetized rats showed far fewer discharges evoked by innocuous than by noxious somatosensory stimuli (Richards and Taylor, 1982; Chudler et al., 1993), the latter discharges apparently involving, instead, thalamostriatal afferents (Chudler and Dong, 1995). Nonetheless, recent information regarding somatotopic organization and sensitivity to innocuous somatosensory stimuli (Carelli and West, 1991; Cho and West, 1997) could now guide mapping studies during anesthesia by providing stereotaxic coordinates for locating striatal neurons related to each body part and optimal stimulus parameters. The present study tested whether innocuous somatosensory stimulation evokes discharges of striatal neurons during anesthesia. The negative results obtained militate against such mapping and raise questions concerning the generality of many findings obtained from the striatum of anesthetized animals.

\section{MATERIALS AND METHODS}

Recording. Action potentials of single neurons were recorded extracellularly with tungsten microelectrodes (10 M $\Omega$; Haer, Brunswick, ME) with a bandpass filter $(500-8000 \mathrm{~Hz})$. Discrimination of waveforms used two window discriminators in series: first a World Precision Instruments model 121, whose acceptance pulse triggered a BAK Electronics Time Amplitude discriminator model DIS-1, whose acceptance pulse entered the computer and was time-stamped. These potentials were obtained from neurons intrinsic to the striatum and not from fibers of passage. This was confirmed by constructing a "depth profile" of neuronal activity as each electrode was advanced through the neocortex and into the striatum. Immediately ventral to a region containing large spikes characteristic of neurons in deep cortical layers, a "quiet zone" (200-400 $\mu \mathrm{m}$ in distance) was consistently observed in which no neuronal discharges were recorded. Histological reconstruction verified that this quiet zone corresponded to white matter of the corpus callosum or external capsule. Hence, it was concluded that the present electrodes did not detect axonal spikes, including those in axon bundles coursing through the striatum.

Determination of neuronal activity related to individual body parts. The body was divided into 14 regions or categories. Ipsilateral and contralateral differentiations were made for forelimbs, hindlimbs, vibrissae, shoulders, and trunk; the remaining four categories were the head, neck, snout, and oral region (lip, chin, or tongue). Determinations of neuronal discharge in relation to a particular category or body part were accomplished by listening through headphones to the audio record (amplified bandpass filter output) while testing at each recording site during passive manipulation and/or cutaneous stimulation of each of the 14 body parts. Each responsive neuron discharged during stimulation of only one body part and thus was assigned unambiguously to a particular category. Cutaneous stimulation was delivered via a handheld probe $(2 \mathrm{~mm}$ in diameter), calibrated to deliver $1-2 g$ of force. Only non-noxious stimulation was administered. The occurrence of spontaneous or evoked movements contributed to the identification of neurons in certain categories (limbs, neck, and oral). Further details of all procedures used for the somatosensory exam have been reported previously (Carelli and West, 1991; Cho and West, 1997). In experiments in chronically implanted animals, care was taken to administer somatosensory stimulation in the predrug condition in a manner that could be replicated in the anesthetized condition. Consistent with this, trials containing any visible active movement were excluded from analysis. Furthermore, experiments in which the same single neuron was recorded across awake and anesthetized conditions were performed only on neurons that fired during cutaneous stimulation or passive manipulation and not on neurons that fired exclusively during active movement.

Acute anesthetized preparations. Long-Evans male rats (Charles River Laboratories, Wilmington, MA), $>90 \mathrm{~d}$ of age (300-350 gm), were anesthetized by intraperitoneal injections of (1) sodium pentobarbital $(n=6 ; 35 \mathrm{mg} / \mathrm{kg})$ supplemented with chloral hydrate $(175 \mathrm{mg} / \mathrm{kg})$ or of (2) ketamine hydrochloride $(n=1 ; 100 \mathrm{mg} / \mathrm{kg})$. Body temperature was monitored via a rectal probe (Yellow Springs Instruments model 43TA) and maintained between 35 and $37^{\circ} \mathrm{C}$ with a heating pad (American Medical Systems Aquamatic K-20). A hole was drilled unilaterally in the skull overlying the lateral striatum, and the exposed cortex was covered with mineral oil. Electrodes were lowered vertically, while delivering somatosensory stimulation and searching for spontaneous or evoked neural discharges.

Chronically implanted preparations. A separate group of subjects $(n=$ 12) was surgically prepared for recording in the awake, unrestrained state by implantation of a miniature microelectrode drive (microdrive) assembly (Josef Biela Engineering, Anaheim, CA). Details of the surgical preparation, microdrive, and behavioral chamber have been reported (Deadwyler et al., 1979; West and Woodward, 1984; Carelli and West, 1991). The microdrive base was attached to either side (level skull) and aimed at the lateral striatum, either (1) at medial-lateral, $6.0 \mathrm{~mm}$, and anterior-posterior, 0 to $-0.3 \mathrm{~mm}$, at an angle of $30-45^{\circ}$ toward the midline; (2) at medial-lateral, $3.6 \mathrm{~mm}$, and anterior-posterior, $+0.5 \mathrm{~mm}$, at an angle of $8^{\circ}$ away from the midline; or (3) at medial-lateral, $3.5 \mathrm{~mm}$, and anterior-posterior, $+0.5 \mathrm{~mm}$, parallel to the dorsoventral axis, i.e., perpendicular to the level skull. Recording sessions began 1 week after surgery. The microdrive was equipped daily with a tungsten microelectrode (10 $\mathrm{M} \Omega$; Haer). Each complete, manual rotation of the outer cylinder of the microdrive advanced the electrode $400 \mu \mathrm{m}$ (without rotating the electrode).

Electrodes were advanced through the striatum in increments of 25-50 $\mu \mathrm{m}$, each increment constituting a separate recording site that underwent a complete somatosensory exam. All data are reported in terms of $50 \mu \mathrm{m}$ increments to maximize the number of sites tested and yet to avoid sampling the same neuron twice. The information regarding somatosensory-evoked discharges at all sites in a single electrode track was used to construct a depth profile for that track.

For certain experiments, anesthetics were administered to chronically implanted animals. Sodium pentobarbital (Abbott Labs, Irving, TX), chloral hydrate (Sigma, St. Louis, MO), urethane (ethyl carbamate; Sigma), and ketamine hydrochloride (Phoenix Scientific, St. Joseph, MO) were administered by intraperitoneal injection. Metofane (methoxyflurane; Mallinckrodt, Mundelein, IL) was administered via a metofanedampened paper towel inserted into the ventilated behavioral chamber. Animals receiving chloral hydrate were killed for histology (see below) within a week after injection to avoid the complication of adynamic ileum (Fleischman et al., 1977). Animals receiving urethane were killed for histology before regaining full consciousness (within $12 \mathrm{hr}$ ) to avoid carcinogenic effects [Flecknell (1987), his pp 40,67].

The anesthetic state and the recovery from it were assessed similarly for all anesthetics by monitoring typical behavioral signs of anesthesia, including loss of posture and muscle tone, loss of orienting responses to somatosensory examination, and loss of reflex tail movement in response to tail pinch. No attempt was made to differentiate among anesthetics with respect to these measures (Field et al., 1993). Also, no systematic attempt was made to characterize different depths of anesthesia.

Poststimulus time histograms (PSTH) and raster displays were constructed to show stimulus-evoked firing. Evoked firing rates were calculated during the "evoked response epoch," defined for each neuron by visual inspection of PSTHs. Baseline firing rates were calculated from the same PSTH, during the period before stimulus onset ("baseline epoch"). Within the PSTH, this baseline epoch was the most remote from any lingering influence of previous stimulus-evoked discharges (no such influence was evident). Stimuli were presented typically $3 \mathrm{sec}$ apart, but at least $1.5 \mathrm{sec}$ apart. Three methods were used to generate a time-stamp (node) of the approximate onset of each somatosensory stimulus; only one method was used for constructing any given PSTH. These methods were (1) the experimenter's simultaneous key press to trigger the computer, (2) frame-by-frame analysis of videotape recordings in which each video frame was time-stamped by the computer (Carelli and West, 1991), and (3) a DC pulse delivered to the computer instantaneously on contact of a bipolar probe (1-4 $g$ of force) with the animal (Prokopenko et al., 1997). Probes used for cutaneous stimulation were manually held and traveled a total distance of $\sim 3 \mathrm{~cm}$ in $0.15 \mathrm{sec}(\sim 20 \mathrm{~cm} / \mathrm{sec}$ velocity).

Histological reconstruction of electrode positions. After completion of the last recording track in each chronically implanted animal $(n=10$, after excluding one animal injected with pentobarbital and one with urethane), a low-impedance insulated wire (200 $\mu \mathrm{m}$ in diameter) was placed in the same location as that at which a particular neuron had been studied before and after anesthetic or, in other cases, at which a particular neuronal recording had been obtained. The subject was deeply anesthetized with sodium pentobarbital $(150 \mathrm{mg} / \mathrm{kg})$, and an electrolytic lesion $(0.03 \mathrm{~mA} ; 10-30 \mathrm{sec})$ was made at the tip of the wire. Animals were then intracardially perfused with $10 \%$ formalin, and coronal sections were sliced $(50 \mu \mathrm{m}$ thick) and stained with cresyl violet. The 


\begin{tabular}{lcrr}
\hline Table 1. Summary of experiments & & \\
& Chronic & Acute & Total \\
\hline Animals & 12 & 7 & 19 \\
Electrode tracks & $82(7)$ & 37 & 126 \\
Recording sites & $2662(297)$ & 326 & 3285 \\
Neurons & $1924(165)$ & 173 & 2262 \\
$\quad$ Body part & $1068(1)$ & 0 & - \\
$\quad$ Sensory & $595(1)$ & 0 & - \\
Experiments & & & \\
$\quad$ Pentobarbital & 8 & 1 & 2 \\
Ketamine & 1 & & 2 \\
Chloral hydrate & 2 & & 4 \\
$\quad$ Urethane & 4 & 7 & 1 \\
Metofane & 1 & & 23 \\
Total & 16 & & \\
\hline
\end{tabular}

Columns show the number of animals prepared for chronic versus acute electrophysiology and the quantity of data collected from the two preparations. Subcategories of neurons are those related to sensorimotor activity of a specific body part and a (sensory) subset of body part neurons that fired in response to passive manipulation and/or cutaneous stimulation. Data in parentheses are numbers obtained from chronically implanted animals under anesthesia.

location of the lesion was used to verify the locations of all neurons recorded from the animal. This was achieved by accounting for (1) the dorsoventral distance between the lesion site and each recording site, (2) the coordinate and angle of the recording track, and (3) the measured eccentricity of the electrode within the microdrive. The position of any given electrode track was plotted on an enlarged coronal diagram (Paxinos and Watson, 1996) corresponding most closely to its anteriorposterior coordinate.

\section{RESULTS}

\section{General description of the sample}

Depth profiles constructed from 126 electrode tracks contained a total of 3285 sites in the striatum from which electrophysiological recordings were obtained under awake or anesthetized conditions (Table 1). The extracellular action potentials of nearly all recorded neurons (e.g., see Figs. 3-6, waveforms) showed an initial, fast negativity (duration, $0.2 \mathrm{msec}$ ) followed by a slower positivenegative wave (total duration of waveform, 1.5-2.0 msec). Spontaneous firing rates were very low and increased phasically during sensorimotor activity. These characteristics are consistent with those of type II, spiny projection neurons (Kimura, 1990; Gerfen and Wilson, 1996).

Of 2662 sites in 82 tracks through the lateral striatum tested in the awake, unrestrained state, 1924 sites (72\%) exhibited neuronal firing. Of this neuronal sample, 1068 neurons (56\%) fired specifically in relation to sensorimotor activity of an individual body part. Of these 1068 body part neurons, 821 were appropriately tested for responsiveness to somatosensory stimulation (passive manipulation or cutaneous stimulation) of that same body part. The majority, i.e., 595 body part neurons (72\%), showed somatosensory-evoked firing, equaling $27 \%$ of the 2246 sites appropriately tested. The remaining 226 body part neurons did not fire during sensory stimulation but fired only during active movement of the related body part. These 226 "active-only" neurons were not considered further, because they could not be compared equitably between awake and anesthetized conditions. The remaining $44 \%$ of the whole neuronal sample ( 856 neurons) exhibited firing but did not fire in relation to sensorimotor activity of individual body parts; these also were not considered further. These categories and proportions are in general agree- ment with those of two separate striatal samples (Carelli and West, 1991; Cho and West, 1997).

\section{Acute anesthetized preparations}

Twenty-nine electrode tracks were made in six animals anesthetized with pentobarbital (35-45 mg/ kg; supplemented with chloral hydrate at $175 \mathrm{mg} / \mathrm{kg}$ ), and eight tracks were made in one animal anesthetized with ketamine $(100 \mathrm{mg} / \mathrm{kg})$. This sample consisted of 326 striatal recording sites at which somatosensory probing of all body parts was performed; 173 of these sites exhibited spontaneously discharging neurons. Figure 1 demonstrates that these electrode tracks traversed the lateral striatum, which is the location of the somatotopically organized neurons responsive to somatosensory stimulation of individual body parts in awake rats (e.g., Carelli and West, 1991; Cho and West, 1997). However, under anesthesia, not a single case was observed in which a striatal neuron showed somatosensory-evoked firing. In contrast, during the advancing of these electrodes through the somatosensory cortex (toward the striatum), cortical neurons fired during somatosensory stimulation of individual body parts, as documented extensively for SI cortex of pentobarbitalanesthetized rats (Welker, 1971, 1976; Hall and Lindholm, 1974; Chapin and Lin, 1984; Chapin, 1986).

\section{Chronic preparations: effect of pentobarbital on electrode track profiles}

The absence of striatal somatosensory-evoked discharges in anesthetized rats (Fig. 1) thus seems to differ both from the presence of these discharges in unanesthetized rats and the presence of such discharges of SI cortical neurons in anesthetized rats. Although these differences appear to reflect the effects of anesthesia on striatal neurons, it is possible that electrode tracks (Fig. 1) failed in some way to sample responsive striatal neurons. Therefore, a direct comparison of electrode track depth profiles between anesthetized versus awake conditions was made in five chronically implanted rats (four with pentobarbital; one with urethane described later, see Fig. 6). After first making a complete penetration through the lateral striatum in the awake condition, the electrode was retracted, and the animal was given a general anesthetic dose of pentobarbital $(50 \mathrm{mg} / \mathrm{kg})$. After allowing the tissue to settle for $20 \mathrm{~min}$, the penetration was repeated.

All profiles in the awake (Pre) condition revealed, at particular depths, clusters of single neurons that fired in relation to somatosensory stimulation of a particular part of the body (Fig. 2, uppercase letters). In contrast to the Pre condition, repetition of the electrode track 20 min after pentobarbital injection showed not a single neuron that fired in response to somatosensory stimulation in any of the four tracks studied. Two representative profiles are illustrated in Figure 2 (left, middle). This lack of evoked firing was observed in spite of the advantage gained from the first penetration (Pre) of knowing how and where to apply the stimulation at each particular depth. Unlike in the awake state, recordings from neurons in the same track (potentially some of the same neurons) during anesthesia were characterized by a lack of both evoked and, in many cases, spontaneous firing (Fig. 2, blank spaces). Neural activity under anesthesia, sometimes encountered at depths identical to depths at which neurons were recorded in the first track, typically consisted only of a burst of discharges for 1-2 sec immediately after the electrode was advanced, followed by a cessation of all firing.

Two additional experiments were performed in awake animals to test whether this absence of evoked firing on the second 
Figure 1. Locations of all 37 electrode tracks through the lateral striatum of seven acute anesthetized animals. (In 8 cases, 2 tracks were located within $0.1 \mathrm{~mm}$ of each other and are shown as one.) Bold numbers indicate the anterior-posterior coordinate (millimeters from bregma) of each coronal diagram (Paxinos and Watson, 1996). Of 326 recording sites tested, 173 neurons were recorded; not one showed evoked firing in response to somatosensory stimulation. Line lengths indicate the dorsoventral distance of penetration into the striatum of pentobarbital- (solid lines) or ketamine(dashed lines) anesthetized animals. The calibration for all diagrams is shown in the coronal diagram at the lower right; each of the three tracks at -0.80 anteriorposterior is $2.0 \mathrm{~mm}$ in dorsoventral length. In each diagram, medial is to the left, and lateral is to the right. Acb, Nucleus accumbens septi; $c c$, corpus callosum; $C P u$, caudate-putamen; $G P$, globus pallidus.

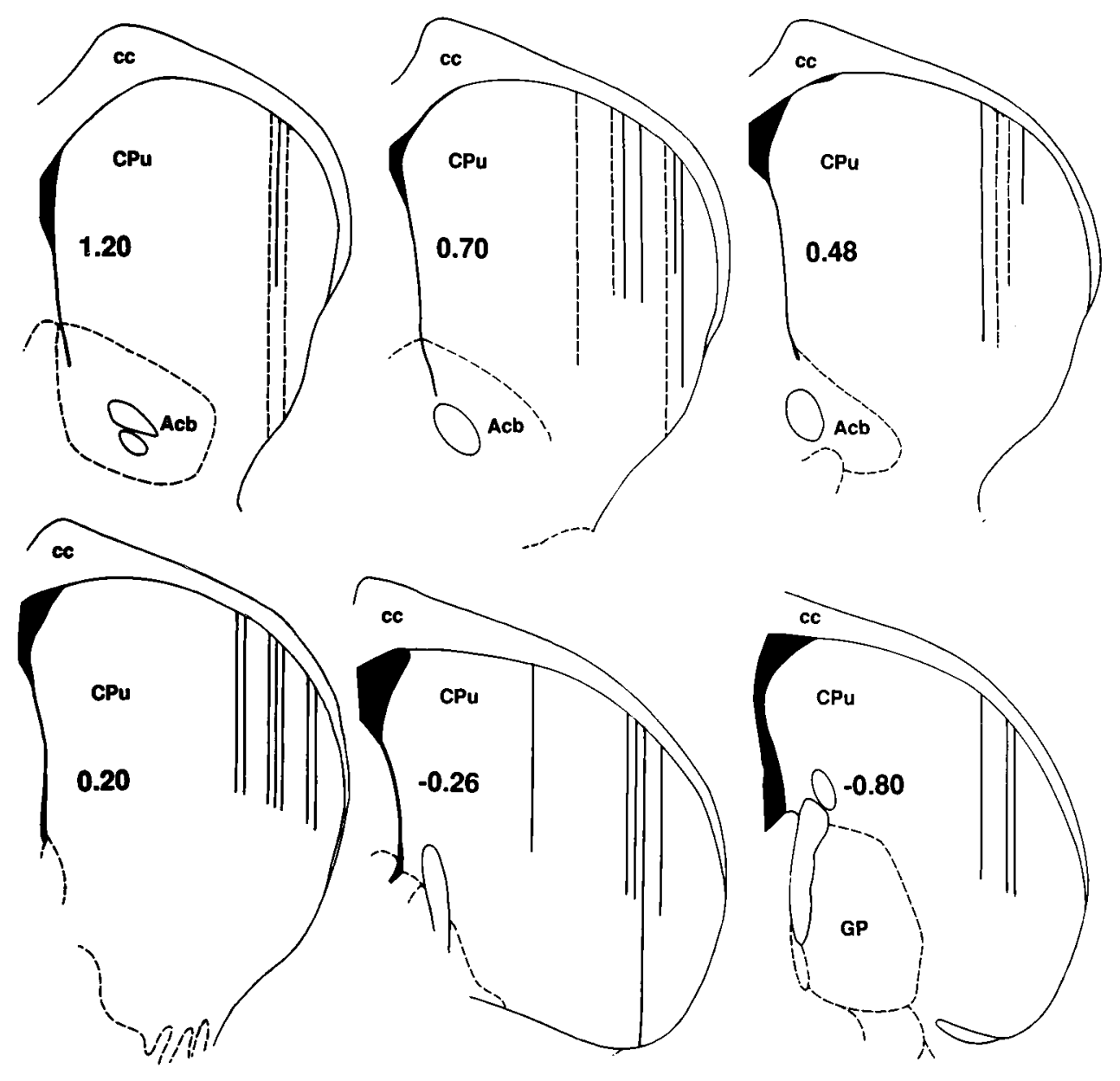

penetration may have been caused simply by some adverse effect of repeating the penetration through the same tissue. In these experiments, the second penetration followed a saline $(0.2 \mathrm{ml})$ rather than a pentobarbital injection. In both cases, the second depth profile closely matched the first, particularly in the important respect that the same body parts were represented at approximately the same depths. The pair of profiles for one such experiment is shown in Figure 2 (right). (Between penetrations, variation in the vertical length measured for a given cluster could be explained by a combination of technical variables, such as (1) tissue dimpling, (2) slight variation in the dorsoventral, mediolateral, or anteroposterior dimensions because of manipulation of the microdrive between penetrations, or (3) between-test variability in the firing of neurons with weak responsiveness to sensory stimulation of a body part.) These results demonstrate the ability of the second penetration to sample the same or similar neurons and homogeneous clusters of neurons which had been sampled in the first penetration. Thus, the lack of sensory-evoked firing during anesthesia (always assessed in the second penetration) cannot be attributed to having compromised the tissue or the electrode during the first penetration.

\section{Chronic preparations: effects of anesthetics on individual neurons}

Results of the above, initial attempts at mapping (by constructing electrode track profiles) in acute anesthetized or chronically implanted rats indicated that such mapping would not be possible under anesthesia induced by pentobarbital/chloral hydrate, ketamine, or urethane (see Fig. 6). To verify that the loss of somatosensory-evoked firing under anesthesia was demonstrable for the same striatal neuron across conditions, additional testing was conducted in nine chronically implanted animals. A single electrode location was maintained to record from one neuron throughout the time course of awake (pre), anesthetized, and awake (recovery) conditions. After first lowering the electrode into the striatum and then allowing it to settle for at least $1 \mathrm{hr}$, we located a single neuron firing in response to a specific somatosensory stimulus that could be repeated reliably under each condition.

\section{Elimination by pentobarbital of individual neuron evoked firing}

Figure 3 shows the effects of pentobarbital at relatively low doses, i.e., $33 \mathrm{mg} / \mathrm{kg}$ (left) and $27 \mathrm{mg} / \mathrm{kg}$ (right), on the firing of two neurons. For one neuron that fired in response to passive manipulation of the contralateral forelimb, pentobarbital reduced evoked firing by $99 \%$, from 17 to 0.17 discharges per stimulus. The baseline mean firing rate was reduced from 2.9 to $0.35 \mathrm{~Hz}$. For another neuron that fired specifically in response to cutaneous stimulation on the contralateral trunk, pentobarbital reduced evoked firing by $96 \%$, from 4.7 to 0.17 discharges per stimulus. The baseline mean firing rate was reduced from 2.1 to $0.16 \mathrm{~Hz}$. In both cases, the mean firing rate during the evoked response epoch showed little or no difference from the baseline mean firing rate under anesthesia, so that no evoked firing could be discerned from background firing. These effects coincided with typical behavioral signs of anesthesia (see Materials and Methods). The low anesthetic level was reflected in the short latency with which 


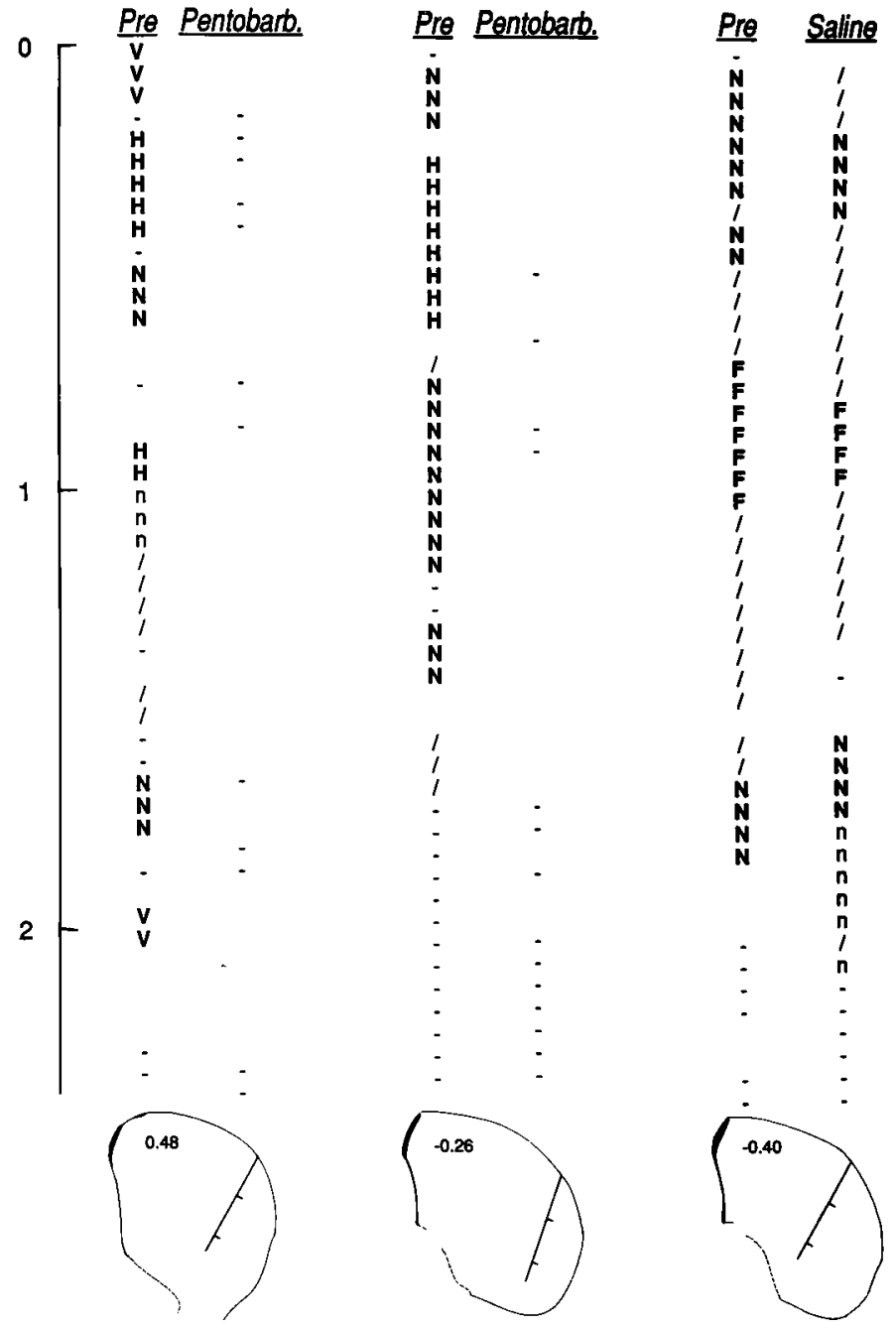

Figure 2. Three pairs of depth profiles through the lateral striatum. For each pair, penetrations were made along the same track before (Pre) and after injection of pentobarbital (Pentobarb.) or saline (Saline). Below each pair is a coronal diagram (Paxinos and Watson, 1996) nearest to the histologically verified location of the track. Tracks are marked in $1 \mathrm{~mm}$ divisions corresponding to the vertical scale at the far left $(0 \mathrm{~mm}=$ point of entry into the striatum). Diagrams are labeled in millimeters anteriorposterior from bregma: 0.48 (left pair), -0.26 , (middle pair), and -0.40 (right pair). A complete somatosensory exam was conducted every $50 \mu \mathrm{m}$. Uppercase letters indicate neurons responsive to somatosensory stimulation of individual body parts $(F$, forelimb; $H$, hindlimb; $N$, neck; $V$, vibrissae). Lowercase letters indicate neurons related only to active movement of a body part ( $n$, neck); active-only firing was excluded from all analyses because it could not be compared between awake and anesthetized conditions. Slash, Neuron related to general movement; hyphen, neuron showing no evoked firing; blank space, no neuron recorded. Profiles were obtained from animals C39 (middle) and C44 (left and right).

animals resumed conscious behaviors: drinking at $30 \mathrm{~min}$ (right) and $60 \mathrm{~min}(l e f t)$ and first locomotion at $45 \mathrm{~min}$ (right) and $70 \mathrm{~min}$ (left) after injection. Both neurons showed gradual recovery of evoked and baseline firing after the animals had recovered behaviorally (Fig. 3).

Similar results (data not shown) were obtained once more in each animal, with at least 1 week intervening between injections. In one animal, the firing of a neuron specifically in response to light tapping of the snout decreased by $90 \%$ (from 8.2 to 0.8 evoked discharges per stimulus) under anesthesia $20 \mathrm{~min}$ after injection of a low dose of pentobarbital $(26 \mathrm{mg} / \mathrm{kg})$. Again (as in Fig. 3), the firing rate during the response epoch was no different from the baseline firing rate. This loss of evoked firing was followed by partial recovery, to $34 \%$ of the response, $3 \mathrm{hr}$ after injection. In contrast, behavioral recovery from anesthesia began with drinking $35 \mathrm{~min}$ after injection, followed by full recovery of all measures at $1.7 \mathrm{hr}$.

In the other animal (departing from the above procedure), the firing of a neuron evoked by passive manipulation of the contralateral hindlimb was recorded during wakefulness at a depth of $900 \mu \mathrm{m}$ into the striatum. When the track was repeated $20 \mathrm{~min}$ after injection of pentobarbital $(35 \mathrm{mg} / \mathrm{kg})$, no trace of evoked firing was recorded at this depth. This absence of evoked firing did not appear to be attributable to spurious testing at depths that did not match those before injection; whereas a cluster of hindlimb neurons was recorded before injection at three consecutive $25 \mu \mathrm{m}$ intervals $(875,900$, and $925 \mu \mathrm{m})$, neurons recorded at these same depths after injection exhibited low spontaneous firing rates and no evoked firing.

\section{Elimination by ketamine of individual neuron evoked firing}

Figure 4 shows the effects of increasing doses of ketamine on the firing of a neuron that discharged in response to cutaneous stimulation specifically of the upper lip. Ten minutes after injection of a subanesthetic dose of $40 \mathrm{mg} / \mathrm{kg}$, the animal was not anesthetized and frequently attempted to move from the experimenter's manual restraint. Nonetheless, evoked firing had been reduced rapidly by $97 \%$, from 11.4 to 0.39 discharges per stimulus (Fig. 4, top vs second panel). Two additional injections of 40 $\mathrm{mg} / \mathrm{kg}$ each (cumulative dose $=120 \mathrm{mg} / \mathrm{kg}$ injected over $35 \mathrm{~min}$ ) were required to eliminate all voluntary movement. At this point (Fig. 4, third panel), evoked firing had ceased, leaving only spontaneous firing (baseline mean of $3.0 \mathrm{~Hz}$ compared with $7.3 \mathrm{~Hz}$ for Pre). Two hours after the first injection, the animal had recovered enough to locomote continuously and to sniff in the corners of the chamber. However, somatosensory-evoked firing of the neuron did not begin to recover until $5 \mathrm{hr}$ after the first injection (Fig. 4, bottom panel).

\section{Elimination by chloral hydrate of individual neuron evoked firing}

Figure 5 shows the effects of chloral hydrate anesthesia (and one subanesthetic dose) on somatosensory-evoked firing of two striatal neurons (left, right). One neuron related specifically to the contralateral forepaw fired in response to a discrete, light tap (1-2 $g$ of force) on the last digit. Evoked (mean $=5.8$ discharges per stimulus) and baseline (mean $=5.5 \mathrm{~Hz}$ ) firing rates were reduced by $>80 \% 20$ min after injection of a low dose of chloral hydrate $(175 \mathrm{mg} / \mathrm{kg})$. The animal was not deeply anesthetized and occasionally made spontaneous body and limb movements. An additional $175 \mathrm{mg} / \mathrm{kg}$ dose, administered $45 \mathrm{~min}$ after the first injection (cumulative dose $=350 \mathrm{mg} / \mathrm{kg}$ ), produced anesthesia. Firing evoked by forepaw stimulation ceased under anesthesia but partially recovered $2.7 \mathrm{hr}$ after the initial injection. The baseline firing rate was similarly affected. At $2.5 \mathrm{hr}$ after the initial injection, the animal was upright and alert, having recovered behaviorally.

In the other animal, a neuron related specifically to activity of the contralateral shoulder fired in response to light stroking of the fur on the shoulder with a soft brush. Evoked firing $($ mean $=9.9$ 

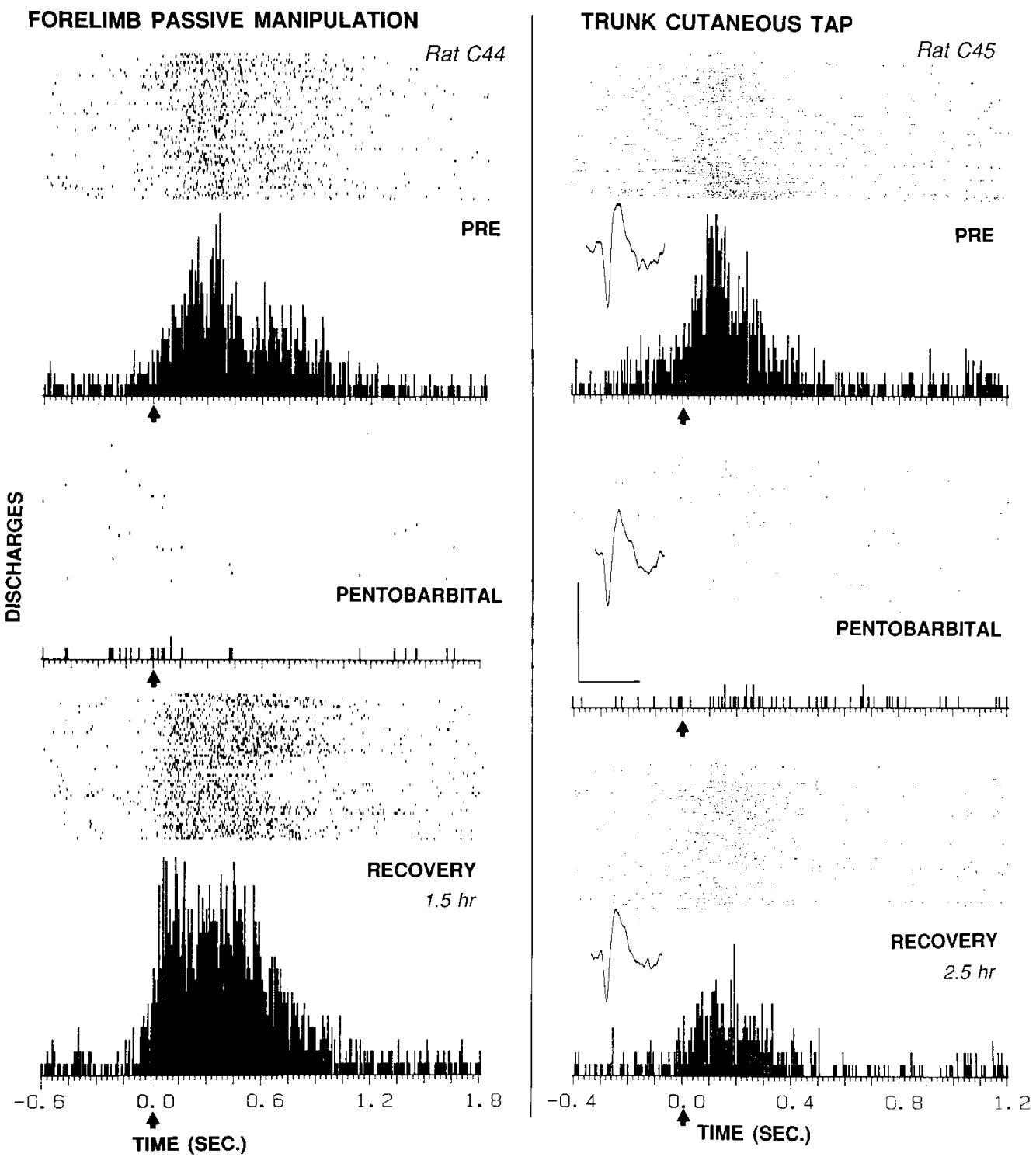

Figure 3. Effects of pentobarbital (left, $33 \mathrm{mg} / \mathrm{kg}$; right, $27.4 \mathrm{mg} / \mathrm{kg}$ ) on somatosensory evoked firing of two striatal neurons in chronically implanted animals. In each column, the raster and PSTH below it display firing of one neuron before (top), during (middle), and after partial or complete recovery (bottom) from pentobarbital anesthesia. Arrows at time 0 indicate the approximate stimulus onset. Left, Neuron responsive to passive manipulation of the contralateral forelimb in rat C44. Evoked discharges per stimulus were 17 (Pre), 0.17 (Pentobarb.), and 29 (Recovery). The evoked response epoch was time 0 to $1.0 \mathrm{sec}$; the baseline epoch was -0.6 to $-0.1 \mathrm{sec}$. The stimulus duration ranged between 0.5 and $1.0 \mathrm{sec}$. The pentobarbital PSTH was taken $40 \mathrm{~min}$ after injection. The number of sweeps in each condition was 53. Right, Neuron with receptive field on the contralateral, dorsal trunk between the forelimb and hindlimb in rat C45. Evoked discharges per stimulus were 4.7 (Pre), 0.17 (Pentobarb.), and 1.8 (Recovery). The pentobarbital PSTH was taken 20 min after injection. The evoked response epoch was time 0 to $0.35 \mathrm{sec}$; the baseline epoch was -0.4 to -0.1 sec. The stimulus duration ranged between 0.1 and $0.3 \mathrm{sec}$. The number of sweeps in each condition was 150. Inset, Representative neural waveform in this and subsequent figures was maintained throughout the experiment, indicating no change in electrode position. Waveform calibration: $0.2 \mathrm{mV}, 1.0 \mathrm{msec}$. Location of each neuron: $0.8-1.0 \mathrm{~mm}$ (left) and $0.4-0.5 \mathrm{~mm}$ (right) inside the dorsolateral edge of the striatum, as in the electrode tracks at the bottom of Figure 2.

discharges per stimulus) ceased, and the baseline firing rate $($ mean $=1.0 \mathrm{~Hz}$ ) was virtually eliminated after a single injection of an anesthetic dose $(400 \mathrm{mg} / \mathrm{kg})$ of chloral hydrate (Fig. 5, right, 20 min after injection). Both neural measures showed partial recovery by the end of the experiment, $5 \mathrm{hr}$ after injection. At that time the animal had recovered upright posture and was orienting to various somatosensory stimuli, having begun to locomote at 2.8 hr after injection.

In both animals, during general anesthesia, the spontaneous firing rate was near zero, except for rare, isolated discharges (Fig. 5 , inset waveforms).

\section{Elimination by urethane of individual neuron evoked firing}

Somatosensory-evoked firing was studied in four additional animals before and after intraperitoneal injection of urethane. Three animals received a single dose of $1.3 \mathrm{gm} / \mathrm{kg}$. One animal (N4) was not anesthetized by this dose (perhaps because of accumulation of drug in the adipose tissue of this animal, which weighed $0.5 \mathrm{~kg}$ and was $>6$ months of age) and therefore received subsequent injections so that the cumulative dose was $2.2 \mathrm{gm} / \mathrm{kg}$. In all four animals, urethane eliminated evoked firing.

Figure 6 (top) shows the effects of urethane in two animals that 


\section{Tap Upper LIp}

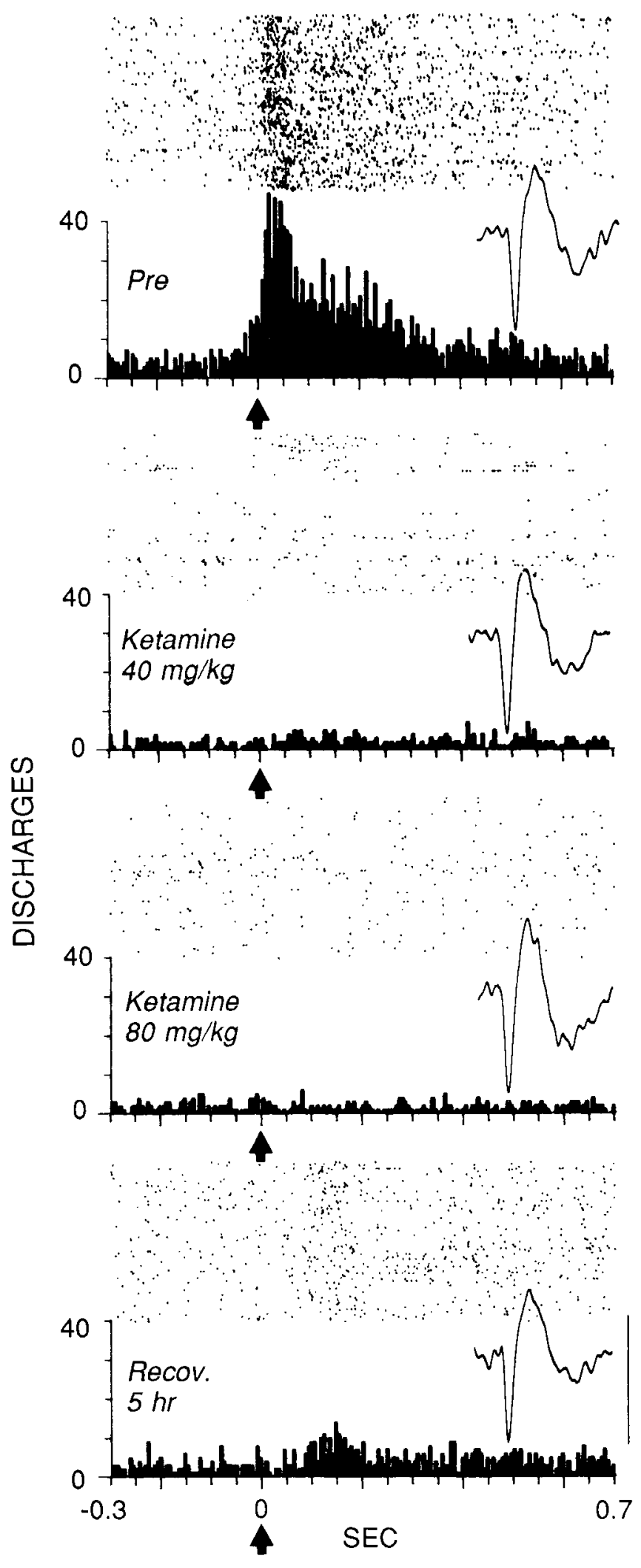

Figure 4. Elimination by ketamine of the evoked firing of a striatal neuron in response to light cutaneous stimulation in chronically implanted animal. The upper lip was near the center of the receptive field, which included the perioral area and snout. Each of four panels shows the raster, PSTH, and representative waveform of the neuron at different stages of were fully anesthetized at the $1.3 \mathrm{gm} / \mathrm{kg}$ dose. In rat N3, the firing of a neuron evoked by passive extension of the contralateral forelimb was eliminated, decreasing from 4.4 to 0.11 discharges per stimulus $2 \mathrm{hr}$ after injection. At this time, the firing rate during the response epoch was no different from the baseline firing rate. The baseline mean firing rate was reduced from 1.2 to $0.27 \mathrm{~Hz}$. At $3 \mathrm{hr}$ after injection, a small evoked discharge $(2.5 \%$ of control) corresponded to transient variations in the depth of anesthesia (see below). Depth profiles (48 sites tested before and $4 \mathrm{hr}$ after injection) in this animal showed somatosensory-evoked firing at 19 sites before injection but at only one site $4 \mathrm{hr}$ after injection.

In rat $\mathrm{C} 117$, firing evoked specifically by cutaneous stimulation of the contralateral perioral area ceased, decreasing from 1.1 to 0 discharges per stimulus $2 \mathrm{hr}$ after injection of urethane. The spontaneous firing rate, compared with a mean of $1.1 \mathrm{~Hz}$ before injection, consisted only of rare, isolated discharges (Fig. 6, inset waveform).

Similar elimination of evoked firing was observed in the other two animals (Fig. 6, bottom). In rat N4, the firing of a neuron in response specifically to cutaneous stimulation of the contralateral trunk was reduced by $88 \%$, from 2.4 to 0.3 discharges per stimulus, $45 \mathrm{~min}$ after the last injection of urethane (cumulative dose $=$ $2.2 \mathrm{gm} / \mathrm{kg}$ ). The baseline mean firing rate was slightly increased from 0.65 to $0.85 \mathrm{~Hz}$, so that the baseline $(0.85 \mathrm{~Hz})$ differed little from the firing rate in the response epoch $(0.99 \mathrm{~Hz})$ during anesthesia. In rat N2, firing evoked specifically by cutaneous stimulation of the contralateral perioral area ceased, decreasing from 4.8 to 0.03 discharges per stimulus 20 min after injection of urethane $(1.3 \mathrm{mg} / \mathrm{kg})$. The baseline mean firing rate was reduced from 5.5 to $0.36 \mathrm{~Hz}$.

In all four animals, a low level of evoked firing returned later (Fig. 6, e.g., rat N3, PSTH at $3 \mathrm{hr}$ and depth profile, one forelimb neuron at $4 \mathrm{hr}$; Rat C117, PSTH at $4 \mathrm{hr}$ ). This corresponded, in every case, to signs of the weakening effects of urethane, i.e., chewing or movements of the head or limbs. These episodes were transient, brief interruptions of otherwise prolonged periods of anesthesia. No assessment was made of recovery from urethane anesthesia, which can exceed 24 hr (Field et al., 1993).

\section{Elimination by metofane of individual neuron evoked firing}

Similar results were obtained during metofane anesthesia. Figure 7 shows the firing of a "neck" neuron that discharged during passive vertical head movement (achieved by gently manipulating the headstage of the animal's harness). Evoked firing was greatest in the Pre condition (data not shown because of a technical problem) but ceased in the anesthetized condition. The neuron exhibited 0.19 evoked discharges per stimulus under anesthesia. This was $12 \%$ of the 1.6 evoked discharges per stimulus observed $2 \mathrm{hr}$ later, at which time evoked firing had partially recovered and

$\leftarrow$

the experiment. Top panel (Pre), Control response during the alert state before injection. Second panel, Ten minutes after injection of a subanesthetic dose of ketamine ( $40 \mathrm{mg} / \mathrm{kg}$, i.p.). Third panel, After two additional injections of ketamine, $40 \mathrm{mg} / \mathrm{kg}$ each. Bottom panel, Partial recovery of evoked firing $5 \mathrm{hr}$ after the initial injection. The number of sweeps in each condition was 100. The average stimulus duration (determined from videotape) was $100 \mathrm{msec}$. The evoked response epoch was time 0 to 0.35 sec; the baseline epoch was -0.3 to -0.05 sec. Each tick on the $x$-axis $=$ $50 \mathrm{msec}$; each bin $=6 \mathrm{msec}$. Arrows at time 0 indicate the approximate stimulus onset. Waveform calibration (bottom right): vertical bar, $0.2 \mathrm{mV}$; duration of each trace, $2.0 \mathrm{msec}$. 
CHLORAL HYDRATE

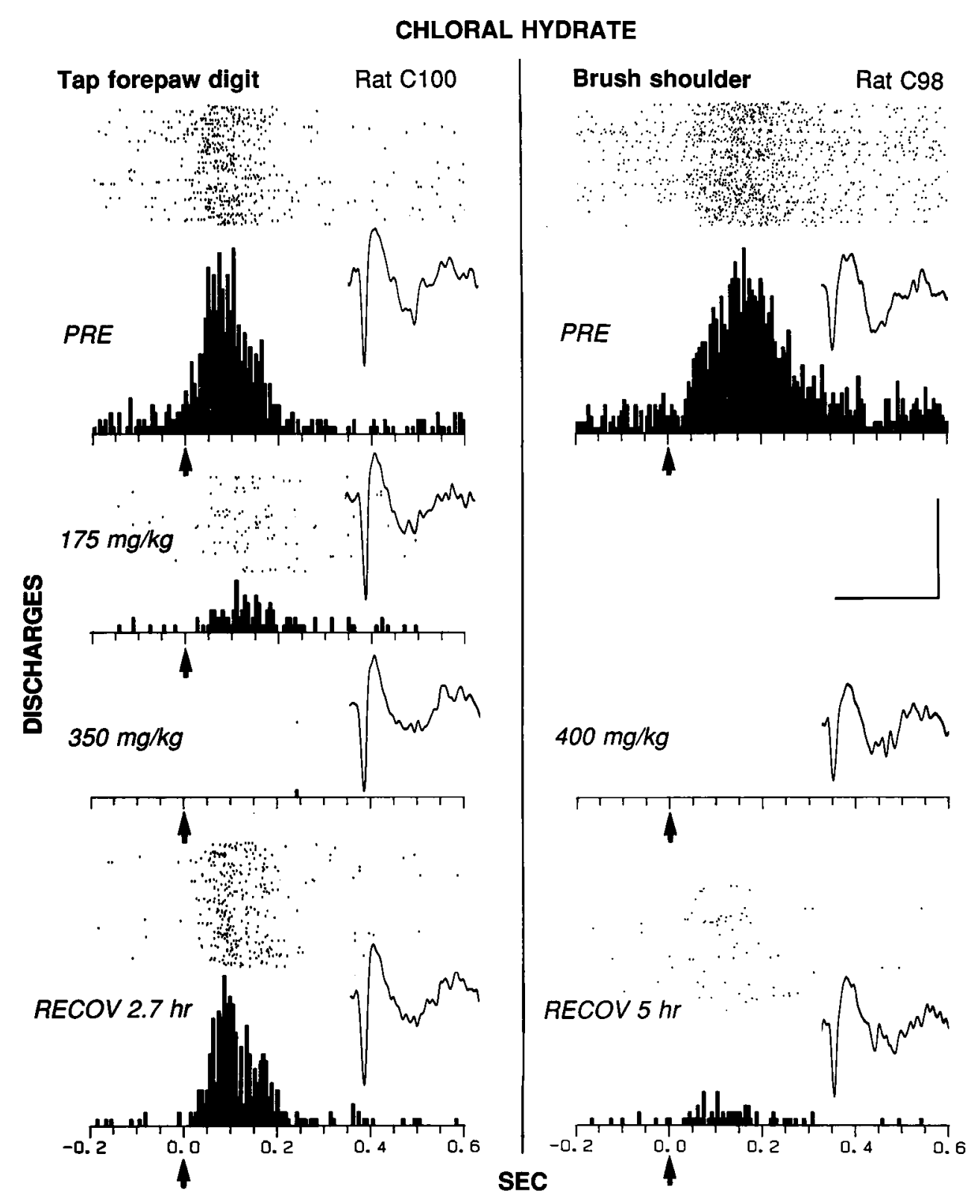

brief metofane anesthesia during installation of the recording apparatus, somatosensory-evoked discharges of striatal neurons are not observed until after behavioral recovery.

\section{Histology}

All recordings were verified to have been obtained from the lateral striatum as follows. Experiments were performed only
Figure 5. Elimination of cutaneous evoked discharges of two striatal neurons (left and right) in chronically implanted animals during chloral hydrate anesthesia. The raster, PSTH, and representative waveform of each neuron are shown for control (PRE) and for each dose and time period after injection. Left , The receptive field of the neuron included the whole contralateral forepaw up to the elbow in rat $\mathrm{C} 100$. The evoked response epoch was time 0 to $0.2 \mathrm{sec}$; the baseline epoch was -0.2 to $0 \mathrm{sec}$. The duration of the tap ranged between 0.1 and $0.2 \mathrm{sec} ; 75$ sweeps were in each condition. Right, The neuron responded to soft brushing of the contralateral shoulder (brush tip, $5 \mathrm{~mm} \times 10$ $\mathrm{mm}$; bristle length, $20 \mathrm{~mm}$ ) in rat C98. The evoked response epoch was time 0 to $0.35 \mathrm{sec}$; the baseline epoch was -0.2 to 0 sec. The duration of the brush stroke was $\sim 0.3 \mathrm{sec}$; 90 sweeps were in each condition. Histological analysis verified that both neurons were located in the striatum, within $0.5 \mathrm{~mm}$ of its dorsolateral edge, as in the electrode track at the bottom left of Figure $2(4.0 \mathrm{~mm}$ lateral to the midline; $0.5 \mathrm{~mm}$ anterior to bregma). Bin width $=$ $6 \mathrm{msec}$. Each tick on the $x$-axis $=50 \mathrm{msec}$. Arrows at time 0 indicate the approximate stimulus onset. Calibration (bars at right): for PSTHs, vertical bar, 20 discharges per bin; for waveforms, horizontal bar, 2.0 $\mathrm{msec}$, and vertical bar, $0.15 \mathrm{mV}($ left $)$ and $0.12 \mathrm{mV}$ (right).
These results are representative of our observations (unpub lished) that, when animals in other studies occasionally require

behavioral measures of anesthesia had fully recovered. In the anesthetized condition, it is likely that most discharges during the epoch were spontaneous rather than evoked given that the mean firing rate during this epoch was $0.37 \mathrm{~Hz}$, compared with $0.33 \mathrm{~Hz}$ in the baseline epoch under anesthesia.

Figure 6. Elimination of somatosensory-evoked discharges of striatal neurons by urethane in four chronically implanted animals. Far left , Two electrode track profiles through the striatum $(50 \mu \mathrm{m}$ increments) obtained from rat N3 before (Pre) and $4 \mathrm{hr}$ after injection of urethane (1.3 gm/ $\mathrm{kg})$. Pre profile (left) was obtained first; then the electrode was raised to the dorsalmost position to record the activity of the forelimb neuron (shown in top PSTH of top left quadrant). Then urethane was injected, and the activity of the same forelimb neuron was recorded for the next $4 \mathrm{hr}$, after which the second profile (4 hr) was obtained. Below the profiles, a coronal diagram (Paxinos and Watson, 1996) shows their approximate location, $-0.26 \mathrm{~mm}$ (anterior-posterior) and $4.0 \mathrm{~mm}$ (medial-lateral); hash marks are at each millimeter. Uppercase $O$, Neuron responsive to perioral stimulation; lowercase $O$, neuron correlated with licking; hyphen, neuron showing no discharges evoked by somatosensory stimulation. Details are described in the Figure 2 legend. Four quadrants, Histograms (and rasters above each) displaying the discharges of four neurons evoked by somatosensory stimulation in the four animals injected with urethane. Top panel in each quadrant, Awake state before injection. Lower panels in each quadrant, Specific times after injection. Each tick on the $x$-axis $=$ $50 \mathrm{msec}$; bin width $=10 \mathrm{msec}$. Arrows indicate the approximate stimulus onset. For each of the four neurons, a representative waveform is shown from each time period for which a PSTH is displayed. Waveform calibration (bottom left): $0.2 \mathrm{mV} ; 1.0$ sec. Top left quadrant (Figure legend continues), 


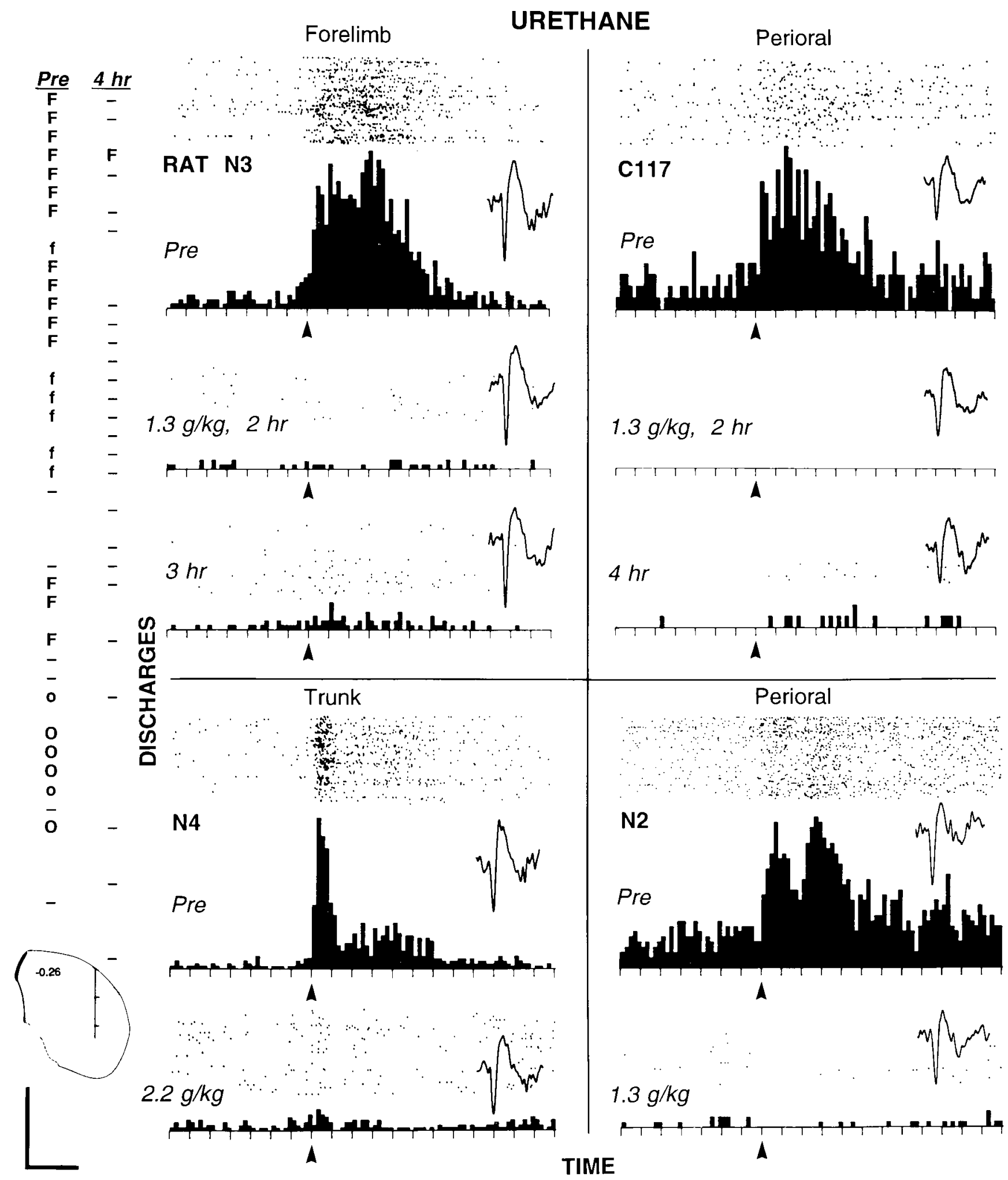

Forelimb neuron recorded at top location of profiles at far left in rat N3. (The neuron showed no evoked firing at 4 hr after injection but showed some evoked discharges in PSTH at $3 \mathrm{hr}$.) The evoked response epoch was 0 to $0.35 \mathrm{sec}$; the baseline epoch was -0.35 to -0.05 sec. Stimulus duration was $\sim 200 \mathrm{msec} ; 150$ sweeps were in each condition. Top right quadrant, Neuron responsive to perioral stimulation recorded in rat C117. The evoked response epoch was 0 to $0.3 \mathrm{sec}$; the baseline epoch was -0.35 to $-0.05 \mathrm{sec}$. Stimulus duration was $\sim 150 \mathrm{msec} ; 200$ sweeps were in each condition. Lower left quadrant, Neuron responsive to cutaneous stimulation of the trunk in rat N4. The evoked response epoch was 0 to $0.3 \mathrm{sec}$; the baseline epoch was -0.35 to $0 \mathrm{sec}$. Stimulus duration was $\sim 100 \mathrm{msec} ; 200$ sweeps were in each condition. Lower right quadrant, Neuron responsive to cutaneous stimulation of the perioral area in rat N2. The evoked response epoch was 0 to $0.25 \mathrm{sec}$; the baseline epoch was -0.35 to 0 sec. Stimulus duration was $\sim 150 \mathrm{msec} ; 100 \mathrm{sweeps}$ were in each condition. 
Figure 7. Elimination of the evoked firing of a striatal neuron in response to passive vertical head movement under metofane anesthesia in rat C44. Right, PSTH was taken with the rat fully anesthetized, $40 \mathrm{~min}$ after insertion of a metofane-dampened towel into the behavioral chamber. (Onset of anesthesia was slow because of ventilation present in the chamber.) Then the metofane towel was removed. Left, PSTH was taken $1.3 \mathrm{hr}$ later, 30 min after recovery of all behavioral measures of anesthesia. Dashed vertical line at time 0 indicates the approximate stimulus onset. Stimulus duration was $\sim 0.8 \mathrm{sec}$. The evoked response epoch was 0.1 to $0.8 \mathrm{sec}$; the baseline epoch was -1.0 to $0 \mathrm{sec}$. Each tick on the $x$-axis $=150 \mathrm{msec} ; 84$ trials were in each condition.

\section{PASSIVE HEAD MOVEMENT}

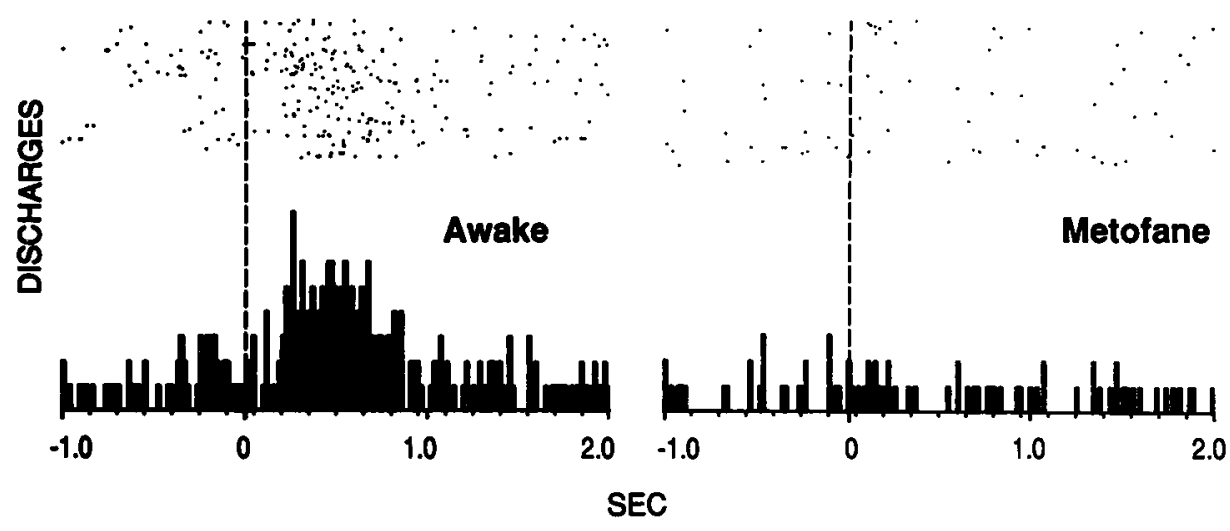

when the electrode track profile through the cortex and striatum exhibited the clear electrophysiological characteristics we have established in the awake rat; as confirmed here in 10 chronically implanted rats, under conditions that meet these electrophysiological criteria, histological sections verified the electrode position to be in the striatum (West et al., 1990; Carelli and West, 1991; Mittler et al., 1994; Cho and West, 1997).

\section{DISCUSSION}

Recording the activity of functionally identified lateral striatal neurons during sensorimotor processing serves as a model for studying naturally evoked corticostriatal transmission to striatal projection neurons. The model was used here to study evoked discharges while administering somatosensory stimuli equitably under awake versus anesthetized conditions but showed only profound loss of evoked firing with each anesthetic tested.

The absence of evoked firing in acutely anesthetized animals (pentobarbital/chloral hydrate or ketamine, Fig. 1) was similarly observed in chronically implanted animals; electrode track profiles showed somatosensory-evoked firing during wakefulness (Crutcher and DeLong, 1984a; Cho and West, 1997) but not during anesthesia (pentobarbital or urethane; Figs. 2, 6).

When one neuron was recorded across conditions $(n=12)$, somatosensory-evoked firing, observed during wakefulness, was eliminated by pentobarbital, ketamine, chloral hydrate, urethane, or metofane (Figs. 3-7), despite the knowledge of appropriate stimulus parameters for each neuron. Subsequent recovery of evoked firing and stability of neural waveforms demonstrated that the elimination of evoked firing was not a spurious result of compromised ability to record discharges of the neuron (e.g., because of electrode movement). Similarly, the absence of evoked discharges in acute preparations was likely caused by their elimination by anesthetics rather than by failure to sample from somatosensory-responsive neurons.

Those 12 neurons appear to be representative of somatosensory-responsive striatal neurons, based on the uniformity and magnitude of effects during peak levels of anesthesia. First, evoked firing of every neuron was reduced by an amount approaching 100\%. Second, the more extensive sample of 620 sites tested under pentobarbital, ketamine, or urethane anesthesia was expected to show evoked firing at $\sim 167$ sites [based on 2246 sites tested during wakefulness, of which 595 (27\%) showed evoked firing]. However, no amount of evoked firing, not even in reduced numbers of discharges, was observed at any site (except for one site $4 \mathrm{hr}$ after urethane injection). Therefore, it is likely that more recordings of the evoked firing of one neuron throughout wakefulness versus anesthesia would show similar effects, at least qualitatively. This would support the main conclusion that these anesthetics reduce the likelihood of striatal firing in response to corticostriatal transmission. That these effects are representative of effects on striatum in general is supported indirectly by similar suppressions of spontaneous firing of somatosensory-responsive neurons (present study) and the general population of striatal neurons (Bloom et al., 1965; Wilson and Groves, 1981; Gonon, 1997) by anesthetics.

Data were not collected to allow systematic comparisons among anesthetics regarding dose-effect or duration. Rather, each anesthetic was used independently to test evoked firing at doses suitable for acute electrophysiology. Even at lower doses that did not produce general anesthesia, evoked firing was strongly reduced. Consistent with this, in accord with drug halflives, in no case did neural measures exhibit even partial recovery until after behavioral measures had exhibited full recovery from general anesthetic doses.

Some striatal neurons respond to noxious somatosensory stimulation. However, their distribution, unlike the present sample, does not conform to corticostriatal topography. Instead, such responses seem to involve intralaminar thalamic inputs (Chudler and Dong, 1995) and are observed under urethane (Richards and Taylor, 1982; Abercrombie and Jacobs, 1985) or pentobarbital/ chloral hydrate (Chudler et al., 1993) anesthesia. The few discharges evoked by innocuous stimulation (Richards and Taylor, 1982) may correspond to the transient occurrence of evoked discharges observed here after 3-4 hr of being eliminated by urethane (Fig. 6), during brief interruptions of anesthetic depth.

Demonstrating the loss of evoked firing required controlling for active movement. Although the possibility of active movements during stimulation was selective for wakefulness, such movements did not account for evoked firing. All animals acclimated to somatosensory examination, showing little active movement during manipulations. Furthermore, responsiveness of striatal neurons to passive manipulation is dissociable from active movement (Crutcher and DeLong, 1984b; Liles, 1985). More definitively, when movement did occur during cutaneous stimulation, the trial was discarded, most effectively in videotaped experiments (e.g., Fig. 4). Therefore, the absence of firing evoked by cutaneous stimulation under anesthesia is not attributable to an absence of active movement-related firing selective for this condition. 
If not for these necessary controls, somatosensory-evoked striatal firing would be of most interest during sensorimotor integration or voluntary movement (Lidsky et al., 1985). Perhaps the most important aspect of striatal cell function-processing related to volitional movement-is absent in the anesthetized preparation. Indeed, that absence may partially underlie the absence of evoked firing, if such firing is strictly correlated with behavior. Furthermore, these findings show that some striatal neurons spontaneously fire during anesthesia but fail to exhibit properties fundamental to their normal functioning, without which they cannot be categorized (Crutcher and DeLong, 1984a; Kimura, 1990, 1992; Kimura et al., 1990, 1992; Carelli and West, 1991; Gardiner and Nelson, 1992; Romo et al., 1992; Carelli et al., 1997; Merchant et al., 1997).

Inputs from SI likely mediate these evoked striatal discharges (see introductory remarks). SI was mapped in pentobarbitalanesthetized rats (Welker, 1971, 1976; Hall and Lindholm, 1974; Sanderson et al., 1984), and many similarities to the awake state, as well as certain differences during anesthesia, have been documented (Harding et al., 1979; Duncan et al., 1982; McKenna et al., 1982; Chapin and Lin, 1984; Chapin, 1986; Stryker et al., 1987; Armstrong-James and George, 1988; Bassant et al., 1990; Patel and Chapin, 1990; Simons et al., 1992). Unlike SI, striatal neurons stop firing in response to innocuous somatosensory stimulation during anesthesia, despite the fact that the same stimulation during urethane, pentobarbital, or ketamine anesthesia evokes discharges in SI neurons of layers III and V (Armstrong-James, 1975; Duncan et al., 1982; Lamour et al., 1983; Chapin and Lin, 1984; Chapin, 1986; Stryker et al., 1987; Dykes and Lamour, 1988a,b; Metherate et al., 1988; Simons et al., 1992), the latter being the main source of somatosensory input to the matrix of the lateral striatum where the present neurons were recorded (Flaherty and Graybiel, 1993; Kincaid and Wilson, 1996). These SI discharges could supply the coordinated, excitatory synaptic input (Cowan and Wilson, 1994) required by striatal neurons to shift their membrane potentials to the depolarized up state. Indeed, such shifts occur frequently in anesthetized (Wilson and Kawaguchi, 1996; Stern et al., 1997) and unanesthetized rats (Wilson and Groves, 1981). Therefore during anesthesia, evoked firing in cortical layers projecting to the striatum and the presence of depolarizing shifts to the up state, together with the present data, suggest that striatal neurons do receive depolarizing corticostriatal synaptic input produced by natural somatosensory stimulation but stop discharging in response to it. Anesthetics may alter certain striatal mechanisms [e.g., enhance potassium currents or GABAergic chloride currents (Nicoll and Madison, 1982)] that could interact with voltage-dependent potassium currents during the up state to reduce the likelihood of reaching the threshold for action potentials (Calabresi et al., 1987; Cherubini and Lanfumey, 1987; Rutherford et al., 1988; Galarraga et al., 1994; Nisenbaum and Wilson, 1995; Wilson and Kawaguchi, 1996; Stern et al., 1997). Absence of evoked firing may involve a lack of interaction among afferents [cortical, thalamic, or nigral (e.g., Adams et al., 1991; Boix et al., 1993)]. Regardless, using striatal discharges to map during anesthesia does not seem possible, although intracellular recordings could determine whether natural somatosensory stimulation produces shifts to the up state.

During anesthesia, without normal sensorimotor processing in the cortex (e.g., Lemon and Porter, 1976), not only are patterns of corticostriatal glutamatergic synaptic transmission (Spencer, 1976) altered, but also naturally evoked striatal firing that, by all evidence, involves this input ceases. Furthermore, synaptic inter- actions between striatal and dopamine neurons (Freund et al., 1984; Bolam and Smith, 1990; Yoshida et al., 1993; Miller and Abercrombie, 1996) are altered by depressant anesthetics, e.g., pentobarbital, urethane, chloral hydrate, and metofane (Corrodi et al., 1966; Anden et al., 1974; Bergstrom et al., 1984; Ford and Marsden, 1986; Chapman et al., 1990; Hamilton et al., 1992; Boix et al., 1993; Henriksen and Giachino, 1993). During anesthesia, altered dopamine neuron activity (Freeman et al., 1985; Kelland et al., 1990) and transmission to striatal neurons will be compounded by altered glutamatergic activity, because glutamate influences dopamine release (Shimizu et al., 1990; Moghaddam and Bolinao, 1994; Verma and Moghaddam, 1998). Ketamine anesthesia did not alter basal firing rates of dopamine or striatal neurons (Kelland et al., 1990, 1991) or alter striatal ACh release (Sato et al., 1996). Nonetheless, changes in SI (Duncan et al., 1982; Patel and Chapin, 1990) and the present data show that the pattern of natural corticostriatal transmission and its ability to produce striatal discharges are altered by ketamine [possibly by altering thalamocortical mechanisms (Miyasaka and Domino, 1968)]. Ketamine, chloral hydrate, or pentobarbital anesthesia altered basal and opiate-induced release of striatal serotonin (Tao and Auerbach, 1994). In other studies, anesthetics altered measures of serotonin (e.g., Heym et al., 1984; Dringenberg and Vanderwolf, 1995) and acetylcholine (Bloom et al., 1965; Kewitz and Pleul, 1977; Bertorelli et al., 1990; Damsma and Fibiger, 1991; Sato et al., 1996).

Imbalances in striatal neurotransmitters under anesthesia are potent, abnormal influences on pre- and postsynaptic receptors, firing rates, and pharmacological responses. Firing rate itself, which is depressed by these anesthetics, is an important determinant of the effects of stimulant drugs (Pederson et al., 1997) and of glutamate (Kiyatkin and Rebec, 1996) on striatal firing rates in freely moving rats. Together these alterations emphasize limitations in extrapolating from anesthetized preparations. Indeed, recent studies (Mereu et al., 1995; Shi et al., 1997) have questioned results from chloral hydrate-anesthetized rats regarding dopamine receptor-mediated effects on striatal and dopamine cell firing (see also Kelland et al., 1989, 1990, 1991). Whereas the present study demonstrated that certain, normal processes are eliminated during anesthesia, it is imperative to perform the opposite test. Do results of striatal studies in anesthetized preparations obtain during conscious behavior? This has scarcely been tested, despite the knowledge that results differ among preparations (Hernandez-Lopez et al., 1997) and the documentation of over thirty years of anesthetic-induced alterations in striatal transmitters (e.g., Corrodi et al., 1966).

\section{REFERENCES}

Abercrombie ED, Jacobs BL (1985) Dopaminergic modulation of sensory responses of striatal neurons: single unit studies. Brain Res 358:27-33.

Adams F, Schwarting RKW, Boix F, Huston JP (1991) Lateralized changes in behavior and striatal dopamine release following unilateral tactile stimulation of the perioral region: a microdialysis study. Brain Res 553:318-322.

Alexander GE, DeLong MR (1985) Microstimulation of the primate neostriatum. II. Somatotopic organization of striatal microexcitable zones and their relation to neuronal response properties. J Neurophysiol 53:1417-1430.

Anden NE, Magnusson T, Stock G (1974) Effect of anaesthetic agents on the synthesis and disappearance of brain dopamine normally and after haloperidol, $\mathrm{KCl}$ or axotomy. Naunyn Schmiedebergs Arch Pharmacol 283:409-418.

Armstrong-James M (1975) The functional status and columnar organi- 
zation of single cells responding to cutaneous stimulation in neonatal rat somatosensory cortex S1. J Physiol (Lond) 246:501-538.

Armstrong-James M, George MJ (1988) Influence of anesthesia on spontaneous activity and receptive field size of single units in rat Sm1 neocortex. Exp Neurol 99:369-387.

Bassant MH, Baleyte JM, Lamour Y (1990) Effects of acetylcholine on single cortical somatosensory neurons in the unanesthetized rat. Neuroscience 39:189-197.

Bergstrom DA, Bromley SD, Walters JR (1984) Dopamine agonists increase pallidal unit activity: attenuation by agonist pretreatment and anesthesia. Eur J Pharmacol 100:3-12.

Bertorelli R, Hallstrom A, Hurd Y, Karlsson A, Consolo S, Ungerstedt U (1990) Anaesthesia effects on in vivo acetylcholine transmission: comparisons of radioenzymatic and HPLC assays. Eur J Pharmacol 175:79-83.

Bloom FE, Costa E, Salmoiraghi GC (1965) Anesthesia and the responsiveness of individual neurons of the caudate nucleus of the cat to acetylcholine, norepinephrine and dopamine administered by microiontophoresis. J Pharmacol Exp Ther 150:244-252.

Boix F, Mattioli R, Adams F, Huston JP, Schwarting RKW (1993) Peripherally administered substance $\mathrm{P}$ affects extracellular dopamine concentrations in the neostriatum but not in the nucleus accumbens under anesthesia. Brain Res Bull 31:655-660.

Bolam JP, Smith Y (1990) The GABA and substance P input to dopaminergic neurones in the substantia nigra of the rat. Brain Res 529:57-78.

Calabresi P, Misgeld U, Dodt HU (1987) Intrinsic membrane properties of neostriatal neurons can account for their low level of spontaneous activity. Neuroscience 20:293-303.

Carelli RM, West MO (1991) Representation of the body by single neurons in the dorsolateral striatum of the awake, unrestrained rat. J Comp Neurol 309:231-249.

Carelli RM, Wolske M, West MO (1997) Loss of lever press-related firing of rat striatal forelimb neurons after repeated sessions in a lever pressing task. J Neurosci 17:1804-1814.

Chapin JK (1986) Laminar differences in sizes, shapes, and response profiles of cutaneous receptive fields in the rat SI cortex. Exp Brain Res 62:549-559.

Chapin JK, Lin CS (1984) Mapping the body representation in the SI cortex of anesthetized and awake rats. J Comp Neurol 229:199-213.

Chapin JK, Woodward DJ (1981) Modulation of sensory responsiveness of single somatosensory cortical cells during movement and arousal behaviors. Exp Neurol 72:164-178.

Chapin JK, Woodward DJ (1986) Distribution of somatic sensory and active-movement neuronal discharge properties in the MI-SI cortical border area in the rat. Exp Neurol 91:502-523.

Chapman CD, Gazzara RA, Howard SG (1990) Effects of phencyclidine on extracellular levels of dopamine, dihydroxyphenylacetic acid and homovanillic acid in conscious and anesthetized rats. Neuropharmacology 29:319-325.

Cherubini E, Lanfumey L (1987) An inward calcium current underlying regenerative calcium potentials in rat striatal neurons in vitro enhanced by Bay K 8644. Neuroscience 21:997-1005.

Cho J, West MO (1997) Distributions of single neurons related to body parts in the lateral striatum of the rat. Brain Res 756:241-246.

Chudler EH, Dong WK (1995) The role of the basal ganglia in nociception and pain. Pain 60:3-38.

Chudler EH, Sugiyama K, Dong WK (1993) Nociceptive responses in the neostriatum and globus pallidus of the anesthetized rat. J Neurophysiol 69:1890-1903.

Corrodi H, Fuxe K, Hokfelt T (1966) The effects of barbiturates on the activity of the catecholaminergic neurones in the rat brain. J Pharm Pharmacol 18:556-558.

Cowan RL, Wilson CJ (1994) Spontaneous firing patterns and axonal projections of single corticostriatal neurons in rat medial agranular cortex. J Neurophysiol 71:17-32.

Crutcher MD, Alexander GE (1990) Movement-related neuronal activity selectively coding either direction or muscle pattern in three motor areas of the monkey. J Neurophysiol 64:151-163.

Crutcher MD, DeLong MR (1984a) Single cell studies of the primate putamen. I. Functional organization. Exp Brain Res 53:233-243.

Crutcher MD, DeLong MR (1984b) Single cell studies in the primate putamen. II. Relations to direction of movement and pattern of muscular activity. Exp Brain Res 53:244-258.

Damsma G, Fibiger HC (1991) The effects of anesthesia and hypother- mia on interstitial concentrations of acetylcholine and choline in rat striatum. Life Sci 48:2469-2474.

Deadwyler SA, Biela J, Rose G, West M, Lynch G (1979) A microdrive for use with glass microelectrodes in recording from freely-moving rats. Electroenceph Clin Neurophysiol 47:752-754.

DeLong MR, Crutcher MD, Georgopoulos AP (1983) Relations between movement and single cell discharge in the substantia nigra of the behaving monkey. J Neurosci 3:1599-1606.

Donoghue JP, Herkenham M (1986) Neostriatal projections from individual cortical fields conform to histochemically distinct striatal compartments in the rat. Brain Res 365:397-403.

Dringenberg HC, Vanderwolf CH (1995) Some general anesthetics reduce serotonergic neocortical activation and enhance the action of serotonergic antagonists. Brain Res Bull 36:285-292.

Duncan GH, Dreyer DA, McKenna TM, Whitsel BL (1982) Dose- and time-dependent effects of ketamine on SI neurons with cutaneous receptive fields. J Neurophysiol 47:677-699.

Dykes R, Lamour Y (1988a) Neurons without demonstrable receptive fields outnumber neurons having receptive fields in samples from the somatosensory cortex of anesthetized or paralyzed cats and rats. Brain Res 440:133-143.

Dykes RW, Lamour Y (1988b) An electrophysiological study of single somatosensory neurons in rat granular cortex serving the limbs: a laminar analysis. J Neurophysiol 60:703-724.

Ebrahimi A, Pochet R, Roger M (1992) Topographical organization of the projections from physiologically identified areas of the motor cortex to the striatum in the rat. Neurosci Res 14:39-60.

Evarts EV (1974) Precentral and postcentral cortical activity in association with visually triggered movement. J Neurophysiol 37:373-381.

Favorov O, Sakamoto T, Asanuma H (1988) Functional role of corticoperipheral loop circuits during voluntary movements in the monkey: a preferential bias theory. J Neurosci 8:3266-3277.

Fetz EE, Finocchio DV, Baker MA, Soso MJ (1980) Sensory and motor responses of precentral cortex cells during comparable passive and active joint movements. J Neurophysiol 43:1070-1089.

Field KJ, White WJ, Lang CM (1993) Anesthetic effects of chloral hydrate, pentobarbitone and urethane in adult male rats. Lab Anim 27:258-269.

Flaherty AW, Graybiel AM (1993) Two input systems for body representations in the primate striatal matrix: experimental evidence in the squirrel monkey. J Neurosci 13:1120-1137.

Flaherty AW, Graybiel AM (1994) Input-output organization of the sensorimotor striatum in the squirrel monkey. J Neurosci 14:599-610.

Flecknell PA (1987) Laboratory animal anaesthesia. New York: Academic.

Fleischman RW, McCracken D, Forbes W (1977) Adynamic ileus in the rat induced by chloral hydrate. Lab Anim Sci 27:238-243.

Ford AP, Marsden CA (1986) Influence of anaesthetics on rat striatal dopamine metabolism in vivo. Brain Res 379:162-166.

Freeman AS, Meltzer LT, Bunney BS (1985) Firing properties of substantia nigra dopaminergic neurons in freely moving rats. Life Sci 36:1983-1994.

Freund TF, Powell JF, Smith AD (1984) Tyrosine hydroxylaseimmunoreactive boutons in synaptic contact with identified striatonigral neurons, with particular reference to dendritic spines. Neuroscience 13:1189-1215.

Galarraga E, Pacheco-Cano MT, Flores-Hernandez JV, Bargas J (1994) Subthreshold rectification in neostriatal spiny projection neurons. Exp Brain Res 100:239-249.

Gardiner TW, Nelson RJ (1992) Striatal neuronal activity during the initiation and execution of hand movements made in response to visual and vibratory cues. Exp Brain Res 92:15-26.

Gerfen CR (1989) The neostriatal mosaic: striatal patch-matrix organization is related to cortical lamination. Science 246:385-388.

Gerfen CR, Wilson CJ (1996) The basal ganglia. In: Handbook of chemical neuroanatomy, Vol 12, Integrated systems of the CNS, Pt III (Swanson LW, Bjorklund A, Hokfelt T, eds), pp 371-468. Amsterdam: Elsevier.

Gonon F (1997) Prolonged and extrasynaptic excitatory action of dopamine mediated by $\mathrm{D} 1$ receptors in the rat striatum in vivo. J Neurosci 17:5972-5978.

Hall RD, Lindholm EP (1974) Organization of motor and somatosensory neocortex in the albino rat. Brain Res 66:23-38.

Hamilton ME, Mele A, Pert A (1992) Striatal extracellular dopamine in 
conscious vs. anesthetized rats: effects of chloral hydrate anesthetic on responses to drugs of different classes. Brain Res 597:1-7.

Harding GW, Stogsdill RM, Towe AL (1979) Relative effects of pentobarbital and chloralose on the responsiveness of neurons in sensorimotor cerebral cortex of the domestic cat. Neuroscience 4:369-378.

Henriksen SJ, Giachino J (1993) Functional characteristics of nucleus accumbens neurons: evidence obtained from in vivo electrophysiological recordings. In: Limbic motor circuits and neuropsychiatry (Kalivas PW, Barnes CD, eds), pp 101-124. Boca Raton, FL: CRC.

Hernandez-Lopez S, Bargas J, Surmeier DJ, Reyes A, Galarraga E (1997) D1 receptor activation enhances evoked discharge in neostriatal medium spiny neurons by modulating an L-type $\mathrm{Ca}^{2+}$ conductance. J Neurosci 17:3334-3342.

Heym J, Steinfels GF, Jacobs BL (1984) Chloral hydrate anesthesia alters the responsiveness of central serotonergic neurons in the cat. Brain Res 291:63-72.

Kelland MD, Freeman AS, Chiodo LA (1989) Chloral hydrate anesthesia alters the responsiveness of identified midbrain dopamine neurons to dopamine agonist administration. Synapse 3:30-37.

Kelland MD, Chiodo LA, Freeman AS (1990) Anesthetic influences on the basal activity and pharmacological responsiveness of nigrostriatal dopamine neurons. Synapse 6:207-209.

Kelland MD, Chiodo LA, Freeman AS (1991) Dissociative anesthesia and striatal neuronal electrophysiology. Synapse 9:75-78.

Kewitz H, Pleul O (1977) Inhibition of choline incorporation into brain lipids in rats by urethane, a proposed mechanism of depression of the central nervous system. Naunyn-Schmiedebergs Arch Pharmacol 298:205-210.

Kimura M (1990) Behaviorally contingent property of movementrelated activity of the primate putamen. J Neurophysiol 63:1277-1296.

Kimura M (1992) Behavioral modulation of sensory responses of primate putamen neurons. Brain Res 578:204-214.

Kimura M, Kato M, Shimazaki H (1990) Physiological properties of projection neurons in the monkey striatum to the globus pallidus. Exp Brain Res 82:672-676.

Kimura M, Aosaki T, Ishida A, Watanabe K (1992) Activity of primate putamen neurons is selective to the mode of voluntary movement: visually guided, self-initiated or memory guided. Exp Brain Res 89:473-477.

Kincaid AE, Wilson CJ (1996) Corticostriatal innervation of the patch and matrix in the rat neostriatum. J Comp Neurol 374:578-592.

Kincaid AE, Zheng T, Wilson CJ (1998) Connectivity and convergence of single corticostriatal axons. J Neurosci 18:4722-4731.

Kiyatkin EA, Rebec GV (1996) Dopaminergic modulation of glutamate-induced excitations of neurons in the neostriatum and nucleus accumbens of awake, unrestrained rats. J Neurophysiol 75:142-153.

Kunzle H (1975) Bilateral projections from precentral motor cortex to the putamen and other parts of the basal ganglia. An autoradiographic study in Macaca fascicularis. Brain Res 88:195-209.

Kunzle H (1977) Projections from the primary somatosensory cortex to basal ganglia and thalamus in the monkey. Exp Brain Res 30:481-492.

Lamour Y, Guilbaud G, Willer JC (1983) Rat somatosensory (SmI) cortex: II. Laminar and columnar organization of noxious and nonnoxious inputs. Exp Brain Res 49:46-54.

Lemon RN, Porter R (1976) Afferent input to movement-related precentral neurons in conscious monkeys. Proc R Soc Lond [Biol] 194:313-339.

Lidsky TI, Manetto C, Schneider JS (1985) A consideration of sensory factors involved in motor functions of the basal ganglia. Brain Res Rev 9:133-146.

Liles SL (1979) Topographic organization of neurons related to arm movement in the putamen. In: Advances in neurology (Chase TN, ed). New York: Raven.

Liles SL (1985) Activity of neurons in the putamen during active and passive movements of the wrist. J Neurophysiol 53:217-236.

Liles SL, Updyke BV (1985) Projection of the digit and wrist area of precentral gyrus to the putamen: relation between topography and physiological properties of neurons in the putamen. Brain Res 339:245-255.

Ljungberg T, Apicella P, Schultz W (1992) Responses of monkey dopamine neurons during learning of behavior reactions. J Neurophysiol 67:145-163.

McGeorge AJ, Faull RLM (1989) The organization of the projection from the cerebral cortex to the striatum in the rat. Neuroscience 29:503-537.

McKenna TM, Whitsel BL, Dreyer DA (1982) Anterior parietal cortical topographic organization in macaque monkey: a reevaluation. J Neurophysiol 48:289-317.

Merchant H, Zainos A, Hernandez A, Salinas E, Romo R (1997) Functional properties of primate putamen neurons during the categorization of tactile stimuli. J Neurophysiol 77:1132-1154.

Mereu G, Lilliu V, Vargiu P, Muntoni A, Dianna M, Gessa GL (1995) Depolarization inactivation of dopamine neurons: an artifact? J Neurosci 15:1144-1149.

Metherate R, Tremblay N, Dykes RW (1988) The effects of acetylcholine on response properties of cat somatosensory cortical neurons. J Neurophysiol 59:1231-1252.

Miller DW, Abercrombie ED (1996) Effects of MK-801 on spontaneous and amphetamine-stimulated dopamine release in striatum measured with in vivo microdialysis in awake rats. Brain Res Bull 40:57-62.

Mittler T, Cho J, Peoples LL, West MO (1994) Representation of the body in the lateral striatum of the freely moving rat: single neurons related to licking. Exp Brain Res 98:163-167.

Miyasaka M, Domino EF (1968) Neuronal mechanisms of ketamineinduced anesthesia. Int J Neuropharmacol 7:557-573.

Moghaddam B, Bolinao ML (1994) Glutamatergic antagonists attenuate ability of dopamine uptake blockers to increase extracellular levels of dopamine: implications for tonic influence of glutamate on dopamine release. Synapse 18:337-334.

Nicoll RA, Madison DV (1982) General anesthetics hyperpolarize neurons in the vertebrate central nervous system. Science 217:1055-1057.

Nisenbaum ES, Wilson CJ (1995) Potassium currents responsible for inward and outward rectification in rat neostriatal spiny projection neurons. J Neurosci 15:4449-4463.

Patel IM, Chapin JK (1990) Ketamine effects on somatosensory cortical single neurons and on behavior in rats. Anesth Analg 70:635-644.

Paxinos G, Watson C (1996) The rat brain in stereotaxic coordinates, Second Edition. New York: Academic.

Pederson CL, Wolske M, Peoples LL, West MO (1997) Firing rate dependent effect of cocaine on firing of single neurons in the rat lateral striatum. Brain Res 760:261-265.

Peschanski M, Guilbaud G, Gautron M (1981) Posterior intralaminar region in rat: neuronal responses to noxious and non-noxious cutaneous stimuli. Exp Neurol 72:226-238.

Prokopenko VF, Shevko GN, Voloshin MY, West MO (1997) A peripheral device for intracerebral microinjection in freely moving rats. Brain Res Prot 2:31-34.

Richards CD, Taylor DCM (1982) Electrophysiological evidence for a somatotopic sensory projection to the striatum of the rat. Neurosci Lett 30:235-240.

Romo R, Schultz W (1990) Dopamine neurons of the monkey midbrain: contingencies of responses to active touch during self-initiated arm movements. J Neurophysiol 63:592-606.

Romo R, Scarnati E, Schultz W (1992) Role of primate basal ganglia and frontal cortex in the internal generation of movements. Exp Brain Res 91:385-395.

Rutherford A, Garcia-Munoz M, Arbuthnott GW (1988) An afterhyperpolarization recorded in striatal cells in vitro: effect of dopamine administration. Exp Brain Res 71:399-405.

Sanderson KJ, Welker W, Shambes GM (1984) Reevaluation of motor cortex and of sensorimotor overlap in cerebral cortex of albino rats. Brain Res 292:251-260.

Sato K, Wu J, Kikuchi T, Wang Y, Watanabe I, Okumura F (1996) Differential effects of ketamine and pentobarbitone on acetylcholine release from the rat hippocampus and striatum. $\mathrm{Br} \mathrm{J}$ Anaesth 77:381-384.

Schultz W (1986) Responses of midbrain dopamine neurons to behavioral trigger stimuli in the monkey. J Neurophysiol 56:1459-1462.

Schultz W, Ruffieux A, Aebischer P (1983) The activity of pars compacta neurons of the monkey substantia nigra in relation to motor activation. Exp Brain Res 51:377-387.

Selemon LD, Goldman-Rakic PS (1985) Longitudinal topography and interdigitation of corticostriatal projections in the rhesus monkey. J Neurosci 5:776-794.

Shi WX, Smith PL, Pun CL, Millet B, Bunney BS (1997) D1-D2 interaction in feedback control of midbrain dopamine neurons. J Neurosci 17:7988-7994.

Shimizu N, Duan S, Hori T, Oomura Y (1990) Glutamate modulates 
dopamine release in the striatum as measured by brain microdialysis. Brain Res Bull 25:99-102.

Simons DJ, Carvell GE, Hershey AE, Bryant DP (1992) Responses of barrel cortex neurons in awake rats and effects of urethane anesthesia. Exp Brain Res 91:259-272.

Soso MJ, Fetz EE (1980) Responses of identified cells in post-central cortex of awake monkeys during comparable active and passive joint movements. J Neurophysiol 43:1090-1110.

Spencer HJ (1976) Antagonism of cortical excitation of striatal neurons by glutamic acid diethyl ester: evidence for glutamic acid as an excitatory transmitter in the rat striatum. Brain Res 102:91-101.

Steinfels GF, Heym J, Jacobs BJ (1981) Single unit activity of dopaminergic neurons in freely moving cats. Life Sci 29:1435-1442.

Stern EA, Kincaid AE, Wilson CJ (1997) Spontaneous subthreshold membrane fluctuations in action potential variability of rat corticostriatal and striatal neurons in vivo. J Neurophysiol 77:1697-1715.

Stryker MP, Jenkins WM, Merzenich MM (1987) Anesthetic state does not affect the map of the hand representation within area $3 \mathrm{~b}$ somatosensory cortex in owl monkey. J Comp Neurol 258:297-303.

Tanji J, Kurata K (1985) Contrasting neuronal activity in supplementary and precentral motor cortex of monkeys. I. Responses to instructions determining motor responses to forthcoming signals of different modalities. J Neurophysiol 53:129-141.

Tao R, Auerbach SB (1994) Anesthetics block morphine-induced increases in serotonin release in rat CNS. Synapse 18:307-314.

Trytek ES, White IM, Schroeder DM, Heidenreich BA, Rebec GV (1996) Localization of motor- and nonmotor-related neurons within the matrixstriosome organization of rat striatum. Brain Res 707:221-227.
Verma A, Moghaddam B (1998) Regulation of striatal dopamine release by metabotropic glutamate receptors. Synapse 28:220-226.

Waterhouse BD, Woodward DJ (1980) Interaction of norepinephrine with cerebrocortical activity evoked by stimulation of somatosensory afferent pathways in the rat. Exp Neurol 67:11-34.

Welker C (1971) Microelectrode delineation of fine grain somatotopic organization of Sm1 cerebral neocortex in albino rat. Brain Res 26:259-275.

Welker C (1976) Receptive fields of barrels in the somatosensory neocortex of the albino rat. J Comp Neurol 166:173-190.

West MO, Woodward DJ (1984) A technique for microiontophoretic study of single neurons in the freely moving rat. J Neurosci Methods 11:179-186.

West MO, Carelli RM, Cohen SM, Gardner JP, Pomerantz M, Chapin JK, Woodward DJ (1990) A region of the dorsolateral striatum of the rat exhibiting single unit correlations with specific locomotor limb movements. J Neurophysiol 64:1233-1246.

Wilson CJ, Groves PM (1981) Spontaneous firing patterns of identified spiny neurons in the rat neostriatum. Brain Res 220:67-80.

Wilson CJ, Kawaguchi Y (1996) The origins of two-state spontaneous membrane potential fluctuations of neostriatal spiny neurons. J Neurosci 16:2397-2410.

Yoshida M, Mizoguchi K, Yokoo H, Tanaka T, Ishii H, Emoto H, Koga C, Tanaka M (1993) Muscimol-induced increase in dopamine release and metabolism is not observed in kainic acid-lesioned striatum of conscious rats: an in vivo microdialysis study. Neurosci Lett 162:5-8. 